\title{
Sensorless DTC of IPMSM for embedded systems
}

Tahar Terras, Kada Hartani

Department of Electrical Engineering, Electrotechniqcal Engineering Laboratory, University of Saida, Algeria

\begin{tabular}{|c|c|}
\hline Article Info & ABSTRACT \\
\hline Article history: & The main objective of the present work is to describe the sensorless control \\
\hline Received Apr 19, 2019 & $\begin{array}{l}\text { of interior permanent magnet synchronous motor (IPMSM) for embeded } \\
\text { systems in traction applications using the Model Reference Adaptive System }\end{array}$ \\
\hline Revised Jul 8, 2019 & (MRAS) method for speed estimation. The algorithm of this method has been \\
\hline Accepted Nov 14, 2019 & $\begin{array}{l}\text { adapted with the mathematical model of the motorized wheels electric } \\
\text { vehicle. The command used is the DTC. Sensorless DTC of IPMS in-wheel }\end{array}$ \\
\hline Keywords: & $\begin{array}{l}\text { motor based on MRAS for electric vehicle is simulated by Matlab/Simulink. } \\
\text { The simulation results show the effectiveness of this proposed sensorless }\end{array}$ \\
\hline Direct torque control & DTC control used for embedded system applications. \\
\hline
\end{tabular}

This is an open access article under the CC BY-SA license.

Embeded systems

IPMSM

MRAS observer

\begin{abstract}
The main objective of the present work is to describe the sensorless control of interior permanent magnet synchronous motor (IPMSM) for embeded systems in traction applications using the Model Reference Adaptive System adapted with the mathematical model of the motorized wheels electric The simulation results show the effectiveness of this proposed sensorless DTC control used for embedded system applications.
\end{abstract}

\section{Corresponding Author:}

Tahar Terras,

Department of Electrical Engineering, Electrotechniqcal Engineering Laboratory, University of Saida, BP 138 En-nasr 20000 Saida, Algeria.

Email: t_tahar2000@yahoo.fr

\section{INTRODUCTION}

Embedded networks have become increasingly important. This change is not strange to that of power electronics, quite the opposite. The reliability and robustness offered by static converters when combined with electrical machines have naturally led to their massive use.

Nowadays, interior permanent magnet synchronous motors (IPMSM) are expected to be applied to propulsion systems of electric vehicles for their high power and torque density, high efficiency, large constant power operation region, robust mechanical construction and cost-effectiveness. However, their large torque ripple is an obstacle in practical applications of PMSMs to vehicle propulsion. According to the litterature review, [1,2] gave more attention to reduce the torque ripple in PMS motors for EV traction applications.

For embedded applications, synchronous permanent-magnet motors powered by a converter have good energy efficiency, power density, and high specific torque with the capability to ensure maximum torque from zero speed to base speed and to extend its operation beyond the base speed while ensuring high torque at low ripples thanks to its control. These motors are also known for their low weight and volume. On the other hand, some disadvantages exist such as the high cost of magnets and the demagnetization of permanent magnets at high temperature. The direct torque control for EV-traction means the torque control of a traction motor [3-8]. Thus, the DTC strategy for IPMSM drive is the right candidate for the highperformance control to meet the EV-traction requirements. The major advantage of DTC is the fast and accurate torque response with low torque ripple which is used in the embedded systems [9]. Direct torque control (DTC) applied to asynchronous machines appeared in the 1980s [10]. Its principle is to select one of the eight voltage vectors generated by the different possible configurations of the inverter switches in order to 
maintain the stator flux and the electromagnetic torque inside two hysteresis boundries. Proper application of this principle allows decoupling of the control between the flux and the torque without the need for a coordinate transformation or pulse width modulation for generating the control pulses of the inverter switches [11]. The DTC has a simplified structure, robust with respect to the variations of the parameters of the machine $[12,13]$.

In this paper, we have chosen an NPC (Neutral Point Clamped) distributed-level three-level inverter, which is a very interesting converter for powering high-power machines. This makes it possible to increase the power delivered to the load and to improve the shape of the output voltage so that it is closer to the sinusoid. The general idea of multi-level inverters is to generate a sinusoidal voltage of several voltage levels, typically obtained from DC voltage sources. The increase in the number of levels produces a wave of stairs on the synthesized waveform which approaches the sinusoidal wave with the minimum of harmonics $[14,15]$.

Knowledge of the rotor position of interior permanent magnet synchronous machines (IPMSM) in most variable speed drive systems is required. It is measured by a shaft position sensor or a resolver. Currently, many authors have proposed sensorless control strategies using different control methods for estimating rotor speed and position. [16-20].

In this paper MRAS (Model reference adaptive system) observer is proposed as a sensorless closed loop algorithm to detect speed and position due to their design simplicity and fewer computation requirement compared with other closed-loop model-based methods [21, 22].

There are four sections in this paper. The organization is as follows: In section 2, a mathematical model of the interior permanent magnet synchronous motor (IPMSM) is presented. In section 3, a detailed study of the principle of direct torque control (DTC) for IPMSM, which fed by a NPC structure three-level voltage inverter, is carried out based on the analysis of the Switching table, including five level hysteresis controller of torque and three level hysteresis controller of flux. In section 4, an algorithm for the sensorless drive of IPMSM based on MRAS observer is presented. Simulation and discussion of the Simulink waveforms are presented in section 5. In the end, there is a comprehensive conclusion.

\section{IPMSM MATHEMATICAL MODEL}

The mathematical model of IPMSM in the $\alpha-\beta$ coordinate system can be written as follows; Electrical Equations (1), Flux Equations (2), Currents Equations (3)

$$
\begin{aligned}
& \left\{\begin{array}{l}
v_{s \alpha}=R_{s} i_{s \alpha}+L_{s} \frac{d i_{s \alpha}}{d t}-\omega_{m} \phi_{f} \sin \theta \\
v_{s \beta}=R_{s} i_{s \beta}+L_{s} \frac{d i_{s \beta}}{d t}-\omega_{m} \phi_{f} \cos \theta
\end{array}\right. \\
& \left\{\begin{array}{l}
\phi_{s \alpha}=L_{s} i_{s \alpha}+\phi_{f} \cos \theta \\
\phi_{s \beta}=L_{s} i_{s \beta}+\phi_{f} \sin \theta
\end{array}\right.
\end{aligned}
$$

According to the previous equations and taking as variables of state the components of the stator currents $\left(i_{s \alpha}, i_{s \beta}\right)$ and the speed of rotation $\omega_{m}$, we obtain the following system, Equation of electromagnetic torque (4):

$$
\begin{aligned}
& \int \frac{d i_{s \alpha}}{d t}=-\frac{R_{s}}{L_{s}} i_{s \alpha}+\frac{\phi_{f}}{L_{s}} \omega_{m} \sin \theta+\frac{1}{L_{s}} v_{s \alpha} \\
& \left\{\frac{d i_{s \beta}}{d t}=-\frac{R_{s}}{L_{s}} i_{s \beta}+\frac{\phi_{f}}{L_{s}} \omega_{m} \cos \theta+\frac{1}{L_{s}} v_{s \beta}\right. \\
& \frac{d \omega_{m}}{d t}=-\frac{f}{J} \omega_{m}+\frac{3}{2} \frac{p^{2} \phi_{f}}{j}\left(-i_{s \alpha} \sin \theta+i_{s \beta} \cos \theta\right) \\
& T_{e m}=\frac{3}{2} p\left(\phi_{s \alpha} i_{s \beta}-\phi_{s \beta} i_{s \alpha}\right)
\end{aligned}
$$




\section{PRINCIPLES OF DIRECT TORQUE CONTROL}

Figure 6 shows the block diagram of direct torque control of an IPMSM powered by a two-level voltage inverter. The estimated value of the stator flux is compared to its desired value and the estimated value of the electromagnetic torque is compared to the control torque generated by the speed controller. The resulting flux and torque errors are used by two hysteresis comparators shown in Figure 1 and Figure 2 . The corresponding output values as well as the number of the stator flux position sector are used to select the appropriate voltage vector from FIG. a selection table for generating the pulses for controlling the switches of the inverter. The stator $\alpha-\beta$ axis flux linkages are an integral of the stator EMF:

$$
\begin{aligned}
& \widehat{\phi}_{a s}=\int\left(V_{a s}-R_{s} i_{\alpha s}\right) \cdot d t \\
& \widehat{\phi}_{\beta s}=\int\left(v_{\beta s}-R_{s} i_{\beta s}\right) \cdot d t
\end{aligned}
$$

Module of flux is:

$$
\begin{aligned}
& \hat{\phi}_{s}=\sqrt{\left(\phi_{s \alpha}^{2}+\phi_{s \beta}^{2}\right.} \\
& \hat{T}_{e m}=\frac{3}{2} p\left(\hat{\phi}_{s \beta} i_{s \alpha}-\phi_{s \alpha} i_{s \beta}\right)
\end{aligned}
$$

where $R_{s}$ is stator resistance and $V_{\alpha S}, V_{\beta s}, i_{\alpha s}, i_{\beta s}$ are voltage and current $\alpha, \beta$ components.IPMSM stator winding currents are measured by hall current sensors, and its voltages are calculated by inverter switch state. The actual stator flux and torque are calculated by flux and torque estimator. The actual stator flux and torque are compared with the reference values in two separate hysteresis controllers:

\subsection{Three level hysteresis controller of flux} constraints:

This case, for flux control, the error is located in the three associated intervals that are fixed by the

$$
\left\{\begin{array}{c}
\text { 1) } \varepsilon_{\phi}<\Delta \phi \\
\text { 2) }-\Delta \phi<\varepsilon_{\phi}<\Delta \phi \\
\text { 3) } \quad \varepsilon_{\phi}>\Delta \phi
\end{array}\right.
$$

Thus, the level of the suitable flux is bounded between $-\Delta \phi$ and $\Delta \phi$ and controlled by a two-level hysteresis comparator, Figure 1. As well as its outputs are:

$$
\left\{\begin{array}{l}
C_{f l x}=1 \\
C_{f l x}=0 \\
C_{f l x}=-1
\end{array}\right.
$$

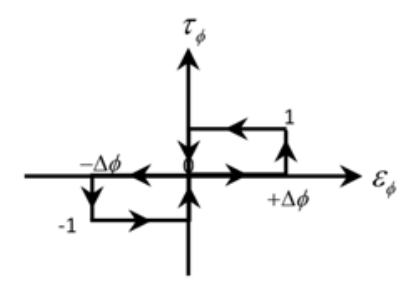

Figure1. Three level hysteresis controller of flux

Int J Pow Elec \& Dri Syst Vol. 11, No. 1, Mar 2020 :86 - 96 


\subsection{Five level hysteresis controller of torque}

The electromagnetic torque is the most important variable for the electromagnetic considerations. Therefore, high performances for torque control are required.

To improve the control of the torque, we associate with the error of the torque five regions defined by the following constraints:

$$
\left\{\begin{array}{l}
\varepsilon_{T}<\Delta_{T \min 2} \\
\varepsilon_{T \min 2}<\Delta_{T}<\varepsilon_{T \min 1} \\
\varepsilon_{T \max 1}<\Delta_{T}<\varepsilon_{T \max 2} \\
\varepsilon_{T}>\Delta_{T \max 2}
\end{array}\right.
$$

The torque control is then performed by a hysteresis comparator with five levels or two upper bands $\left(\Delta_{T \max 1}, \Delta_{T \max 2}\right)$ and two lower bands $\left(\Delta_{T \min 1}, \Delta_{T \min 2}\right.$ illustrated by Figure 2 .

\subsection{Inverter switching table}

Depending on the outputs of the hysteresis controllers and the sector where the stator flux is located, the voltage vectors delivered at the output of the inverter are chosen to maintain the flux and the torque inside the hysteresis bands. The Figure 3 shows an inverter arm.

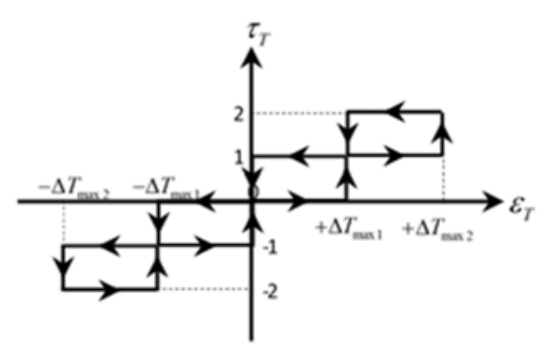

Figure 2. Five level hysteresis Controller of torque

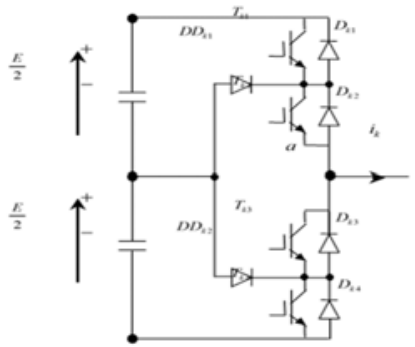

Figure 3. Diagram of an arm of a three-phase inverter with NPC structure.

The 3 states possible switching sequences are summarized in the following Table 1.

Table 1. Switching sequences of the three-level NPC inverter.

\begin{tabular}{ccccc}
\hline$T_{K 1}$ & $T_{K 2}$ & $T_{K 3}$ & $T_{K 4}$ & $v_{a o}$ \\
\hline 1 & 1 & 0 & 0 & $E / 2$ \\
0 & 0 & 1 & 1 & 0 \\
0 & 1 & 1 & 0 & $-E / 2$ \\
\hline
\end{tabular}

From table 2, the 27 voltage vectors delivered by the three-level inverter are represented by a hexagon as shown in the Figure 4.

In order to achieve the direct control of the stator flux and the electromagnetic torque of the machine controlled by a NPC structure 3-level voltage inverter, we have to develop a switching table optimizing the possibilities of the inverter to deliver the necessary commands to increase or decrease the flux and the electromagnetic torque by choosing the stator voltage vectors to be applied. 


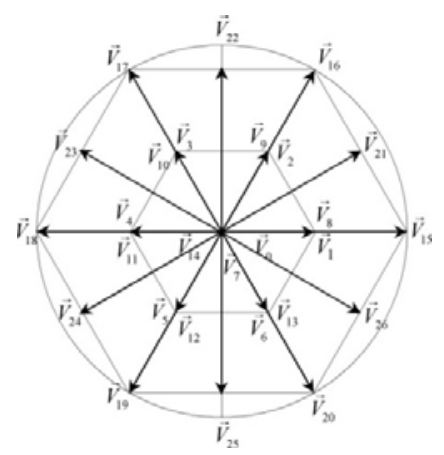

Figure 4. Space vector hexagon of three-level inverter.

Table 2. Switching table for classical DTC

\begin{tabular}{|c|c|c|c|c|c|c|c|c|c|c|c|c|c|}
\hline \multirow{2}{*}{$\tau_{\phi}$} & $\tau_{T}$ & \multicolumn{12}{|c|}{ Stator flux sector } \\
\hline & & 1 & 2 & 3 & 4 & 5 & 6 & 7 & 8 & 9 & 10 & 11 & 12 \\
\hline \multirow{5}{*}{+1} & +2 & $\vec{V}_{21}$ & $\vec{V}_{16}$ & $\vec{V}_{22}$ & $\vec{V}_{17}$ & $\vec{V}_{23}$ & $\vec{V}_{18}$ & $\vec{V}_{24}$ & $\vec{V}_{19}$ & $\vec{V}_{25}$ & $\vec{V}_{20}$ & $\vec{V}_{26}$ & $\vec{V}_{15}$ \\
\hline & +1 & $\vec{V}_{21}$ & $\vec{V}_{2}$ & $\vec{V}_{22}$ & $\vec{V}_{3}$ & $\vec{V}_{23}$ & $\vec{V}_{4}$ & $\vec{V}_{24}$ & $\vec{V}_{5}$ & $\vec{V}_{25}$ & $\vec{V}_{6}$ & $\vec{V}_{26}$ & $\vec{V}_{1}$ \\
\hline & 0 & $\vec{V}_{0}$ & $\vec{V}_{7}$ & $\vec{V}_{14}$ & $\vec{V}_{0}$ & $\vec{V}_{7}$ & $\vec{V}_{14}$ & $\vec{V}_{0}$ & $\vec{V}_{7}$ & $\vec{V}_{14}$ & $\vec{V}_{0}$ & $\vec{V}_{7}$ & $\vec{V}_{14}$ \\
\hline & -1 & $\vec{V}_{26}$ & $\vec{V}_{1}$ & $\vec{V}_{21}$ & $\vec{V}_{2}$ & $\vec{V}_{22}$ & $\vec{V}_{3}$ & $\vec{V}_{23}$ & $\vec{V}_{4}$ & $\vec{V}_{24}$ & $\vec{V}_{s}$ & $\vec{V}_{25}$ & $\vec{V}_{6}$ \\
\hline & -2 & $\vec{V}_{26}$ & $\vec{V}_{15}$ & $\vec{V}_{21}$ & $\vec{V}_{16}$ & $\vec{V}_{22}$ & $\vec{V}_{17}$ & $\vec{V}_{23}$ & $\vec{V}_{18}$ & $\vec{V}_{24}$ & $\vec{V}_{19}$ & $\vec{V}_{25}$ & $\vec{V}_{20}$ \\
\hline \multirow{5}{*}{0} & +2 & $\vec{V}_{22}$ & $\vec{V}_{17}$ & $\vec{V}_{23}$ & $\vec{V}_{18}$ & $\vec{V}_{24}$ & $\vec{V}_{19}$ & $\vec{V}_{25}$ & $\vec{V}_{20}$ & $\vec{V}_{26}$ & $\vec{V}_{15}$ & $\vec{V}_{21}$ & $\vec{V}_{16}$ \\
\hline & +1 & $\vec{V}_{22}$ & $\vec{V}_{3}$ & $\vec{V}_{23}$ & $\vec{V}_{4}$ & $\vec{V}_{24}$ & $\vec{V}_{19}$ & $\vec{V}_{25}$ & $\vec{V}_{20}$ & $\vec{V}_{26}$ & $\vec{V}_{15}$ & $\vec{V}_{21}$ & $\vec{V}_{16}$ \\
\hline & 0 & $\vec{V}_{0}$ & $\vec{V}_{7}$ & $\vec{V}_{14}$ & $\vec{V}_{0}$ & $\vec{V}_{7}$ & $\vec{V}_{14}$ & $\vec{V}_{0}$ & $\vec{V}_{7}$ & $\vec{V}_{14}$ & $\vec{V}_{0}$ & $\vec{V}_{7}$ & $\vec{V}_{14}$ \\
\hline & -1 & $\vec{V}_{25}$ & $\vec{V}_{6}$ & $\vec{V}_{26}$ & $\vec{V}_{1}$ & $\vec{V}_{21}$ & $\vec{V}_{2}$ & $\vec{V}_{25}$ & $\vec{V}_{3}$ & $\vec{V}_{23}$ & $\vec{V}_{4}$ & $\vec{V}_{24}$ & $\vec{V}_{5}$ \\
\hline & -2 & $\vec{V}_{25}$ & $\vec{V}_{20}$ & $\vec{V}_{26}$ & $\vec{V}_{15}$ & $\vec{V}_{21}$ & $\vec{V}_{16}$ & $\vec{V}_{22}$ & $\vec{V}_{17}$ & $\vec{V}_{23}$ & $\vec{V}_{18}$ & $\vec{V}_{24}$ & $\vec{V}_{19}$ \\
\hline \multirow{5}{*}{-1} & +2 & $\vec{V}_{17}$ & $\vec{V}_{23}$ & $\vec{V}_{18}$ & $\vec{V}_{24}$ & $\vec{V}_{19}$ & $\vec{V}_{25}$ & $\vec{V}_{20}$ & $\vec{V}_{26}$ & $\vec{V}_{15}$ & $\vec{V}_{21}$ & $\vec{V}_{16}$ & $\vec{V}_{22}$ \\
\hline & +1 & $\vec{V}_{3}$ & $\vec{V}_{23}$ & $\vec{V}_{4}$ & $\vec{V}_{24}$ & $\vec{V}_{5}$ & $\vec{V}_{25}$ & $\vec{V}_{6}$ & $\vec{V}_{26}$ & $\vec{V}_{1}$ & $\vec{V}_{21}$ & $\vec{V}_{2}$ & $\vec{V}_{22}$ \\
\hline & 0 & $\vec{V}_{0}$ & $\vec{V}_{7}$ & $\vec{V}_{14}$ & $\vec{V}_{0}$ & $\vec{V}_{7}$ & $\vec{V}_{14}$ & $\vec{V}_{0}$ & $\vec{V}_{7}$ & $\vec{V}_{14}$ & $\vec{V}_{0}$ & $\vec{V}_{7}$ & $\vec{V}_{14}$ \\
\hline & -1 & $\vec{V}_{5}$ & $\vec{V}_{25}$ & $\vec{V}_{6}$ & $\vec{V}_{26}$ & $\vec{V}_{1}$ & $\vec{V}_{21}$ & $\vec{V}_{2}$ & $\vec{V}_{22}$ & $\vec{V}_{3}$ & $\vec{V}_{23}$ & $\vec{V}_{4}$ & $\vec{V}_{24}$ \\
\hline & -2 & $\vec{V}_{19}$ & $\vec{V}_{25}$ & $\vec{V}_{20}$ & $\vec{V}_{26}$ & $\vec{V}_{15}$ & $\vec{V}_{21}$ & $\vec{V}_{10}$ & $\vec{V}_{22}$ & $\vec{V}_{17}$ & $\vec{V}_{23}$ & $\vec{V}_{18}$ & $\vec{V}_{24}$ \\
\hline
\end{tabular}

\section{SENSORLESS CONTROL SYSTEM BASED ON MRAS OBSERBVER}

The need to introduce a speed sensor decreases the reliability of the system. Various solutions have been proposed in the control without speed sensor, model adaptive system (MRAS) estimators, adaptive reference model systems are the most attractive approaches because of their simple design, their operating validity in wide ranges speeds (low speeds, high speeds and their adaptation for both types of machines: smooth poles and salient poles). The algorithm of the adaptive reference model system is well known in the sensorless control of induction motors, and it has been proven effective, it is based on the principle in which the two outputs of the two models are compared: an independent model the rotor speed (reference model) AND another model that depends on it (adjustable model) [1, 17, 18, 23, 24].

With Park's transformation, the equations of voltages and fluxes are expressed in the d-q reference by :

$$
\left\{\begin{array}{l}
v_{d}=R_{s} i_{d}+L_{d} \frac{d i_{d}}{d t}-\omega_{m} \varphi_{q} \\
v_{q}=R_{s} i_{q}+L_{q} \frac{d i_{q}}{d t}+\omega_{m} \varphi_{d}
\end{array}\right.
$$




$$
\left\{\begin{array}{l}
\varphi_{d}=L_{d} i_{d}+\varphi_{f} \\
\varphi_{q}=L_{q} i_{q}
\end{array}\right.
$$

By substitution equations (13) and (14) the current model is given by:

$$
\left\{\begin{array}{l}
\frac{d i_{d}}{d t}=-\frac{R_{s}}{L_{d}} i_{d}+\frac{\omega_{m} L_{q}}{L_{d}} i_{q}+\frac{1}{L_{d}} v_{d} \\
\frac{d i_{q}}{d t}=-\frac{R_{s}}{L_{q}} i_{q}-\frac{\omega_{m} L_{q}}{L_{q}} i_{d}+\frac{1}{L_{q}} v_{q}-\frac{\omega_{m} \varphi_{f}}{L_{q}}
\end{array}\right.
$$

The system model can be simplified using equivalent state $i_{d}^{\prime}, i_{q}^{\prime}$ variables and control variables $v_{d}^{\prime}, v_{q}^{\prime}$

$$
\left\{\begin{array}{l}
i_{d}^{\prime}=i_{d}+\frac{\phi_{f}}{L_{d}} \\
i_{q}^{\prime}=i_{q}
\end{array},\left\{\begin{array}{l}
v_{d}^{\prime}=v_{d}+\frac{R_{s} \phi_{f}}{L_{d}} \\
v_{q}^{\prime}=v_{q}
\end{array}\right.\right.
$$

So, equation (15) can be converted to the equation state of the adjustable model of IPMSM with speed angle $\hat{\omega}_{m}$ as the adjustable parameter as follows:

$$
\frac{d}{d t}\left[\begin{array}{l}
\hat{i}_{d}^{\prime} \\
\hat{i}_{q}^{\prime}
\end{array}\right]=\left[\begin{array}{cc}
\frac{-R_{s}}{L_{d}} & \frac{\hat{\omega}_{m} L_{q}}{L_{d}} \\
\frac{-\hat{\omega}_{m} L_{d}}{L_{q}} & -\frac{R_{s}}{L_{q}}
\end{array}\right]\left[\begin{array}{l}
\hat{i}_{d}^{\prime} \\
\hat{i}_{q}^{\prime}
\end{array}\right]+\left[\begin{array}{cc}
\frac{1}{L_{d}} & 0 \\
0 & \frac{1}{L_{q}}
\end{array}\right]\left|\begin{array}{l}
v_{d}^{\prime} \\
v_{q}^{\prime}
\end{array}\right|
$$

Where $\hat{i}_{d}^{\prime}, \hat{i}_{q}^{\prime}$ are the estimated currents in the d-q axis. The reference model is that of the machine. The convergence of the estimated speed $\hat{\omega}_{m}$ to the measured value $\omega_{m}$ is carried out by a suitable adaptation mechanism, and the position of the rotor is obtained by integrating the speed. It should be noted that the critical point in this process is to have an adaptation mechanism that ensures the system stability. The adaptation mechanism is a PI given by (18), (7), (6). Or $\widehat{\omega}_{m}(0)$ is the initial value of the estimated rotor speed, construction of the MRAS is shown in Figure 5.

$$
\widehat{\omega}_{m}=\left(k_{p}+\frac{k_{i}}{s}\right)\left[-\frac{L_{d}}{L_{q}}\left(i_{q}^{\prime}-\hat{i}_{q}\right)+\frac{L_{q}}{L_{d}}\left(i_{d}^{\prime}-\hat{i}_{q}\right)\right]+\hat{\omega}_{m}(0)
$$

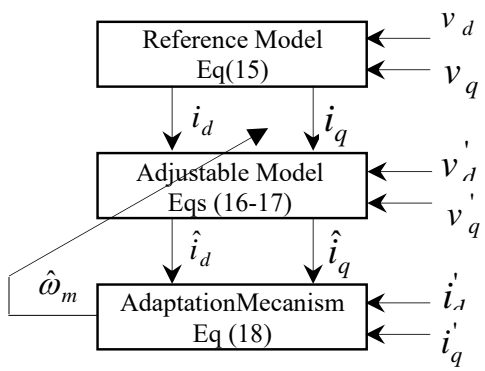

Figure 5. The block diagram control based on MRAS 


\section{SIMULATION RESULTS}

In this section, simulations results via Matlab/Simulink will show the validity and the feasibility of the Sensorless DTC of IPMSM using the Model Reference Adaptive System (MRAS) method for speed estimation. The specifications of the IPMSM used in simulation are given in Table 3 [25].

Table 3. The specifications of the IPMSM used in simulation

\begin{tabular}{ll}
\hline Specification & Value \\
\hline Rated power $P_{N}(k W)$ & 18 \\
Rated DC voltage $U_{d c}(V)$ & 210 \\
Poles pairs $p$ & 4 \\
Stator Resistance $R_{s}(\Omega)$ & 0.03 \\
Inductance of d Axis $(m H)$ & $0.2 \mathrm{e}-3$ \\
Inductance of q Axis $(m H)$ & $0.2 \mathrm{e}-3$ \\
Permanent Magnet Flux of Rotor $\phi_{f}(W b)$ & 0.08 \\
\hline
\end{tabular}

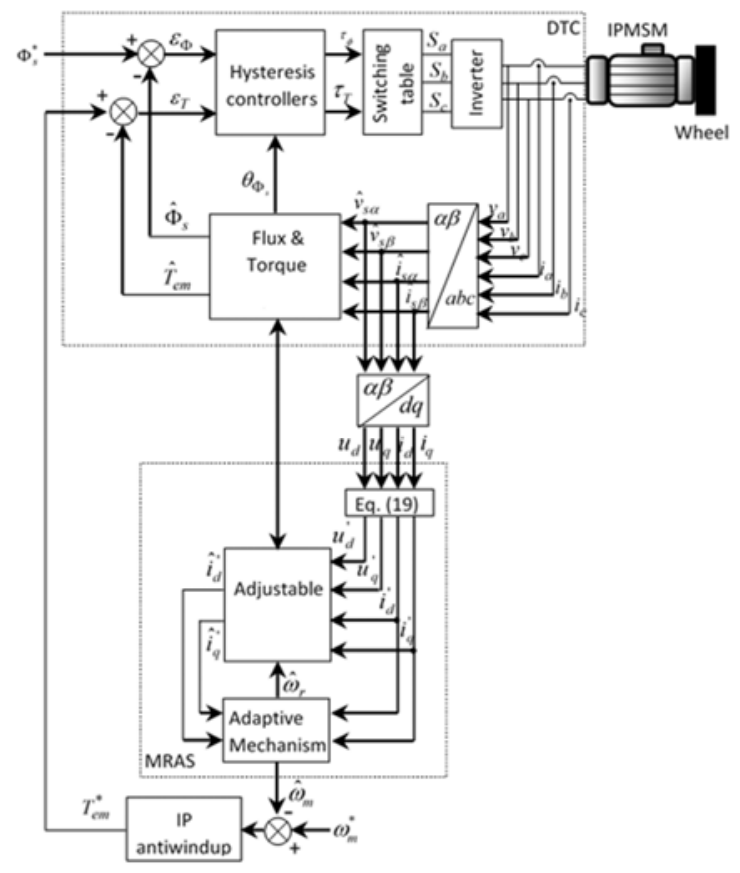

Figure 6. The block diagram DTC method with MRAS Observer

In this simulation study, we consider that all motor parameters are known and constant.The simulation results show that the torque instantaneously responds to the load disturbance at $0.5 \mathrm{~s}$ and follows its reference. Figure 7 (c), Figure 8 (c) and the estimated speed in both directions of rotation perfectly follows the reference without exceeding and without any deformation with a very low observation error Figure7 (a, b). Figure $8(a, b)$, The observed current errors show the good estimation of these variables. Figure 7 (d), Figure 8 (d). Figure 7 (e) shows that the two components of the flux are in quadrature and that the satoric flux vector follows its reference. The response of the flux in the phase plane is practically circular Figure 7 (d). 


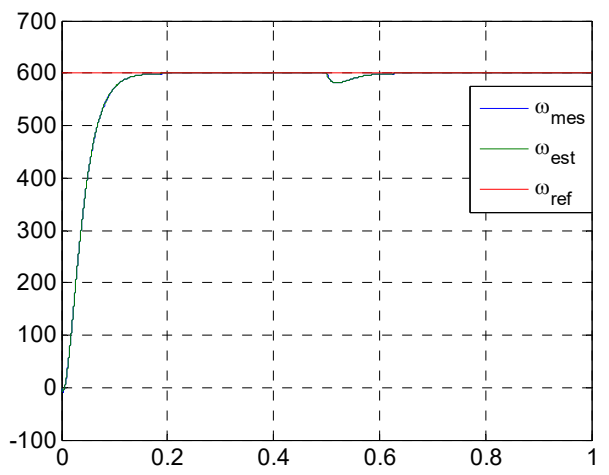

(a) Actual,Estimatd and reference speeds ( $\mathrm{rad} / \mathrm{sec})$ Time (s)

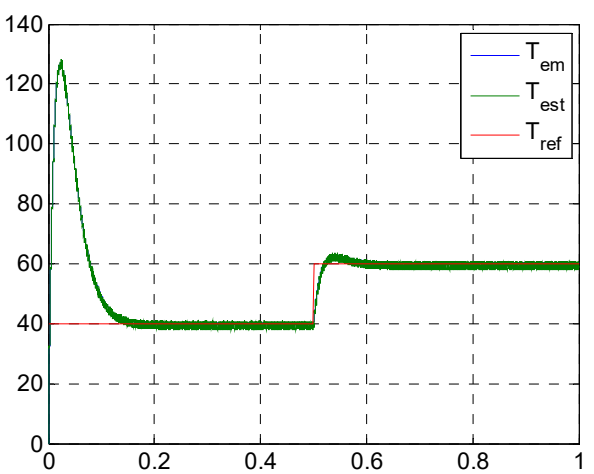

(c) Actual,Estimatd and reference Torques Time (s)

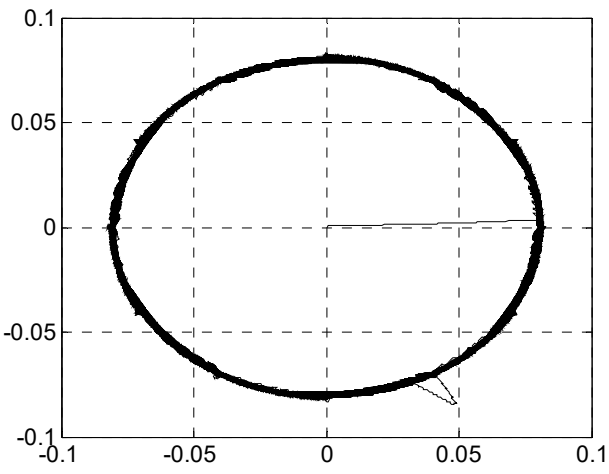

(d) Stator Flux in phase plane.

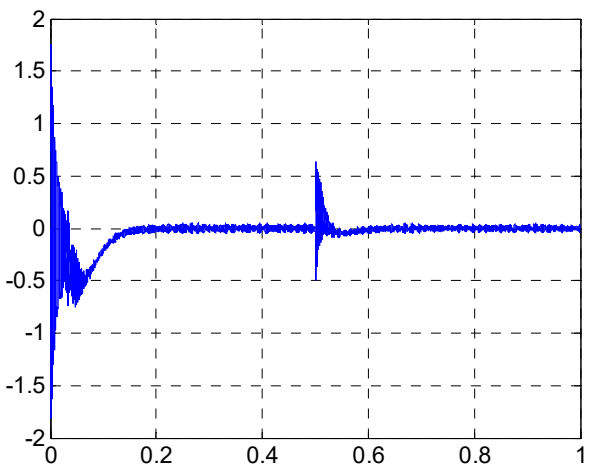

(b) Speed estimation error $(\mathrm{rad} / \mathrm{sec})$ Time (s)

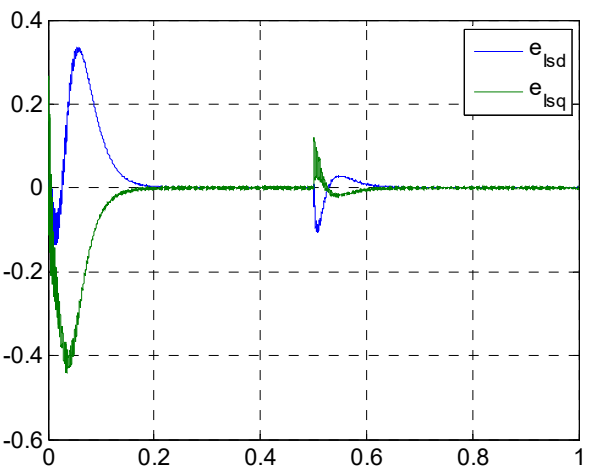

(d) Stator currentserrors (A) Time (s)

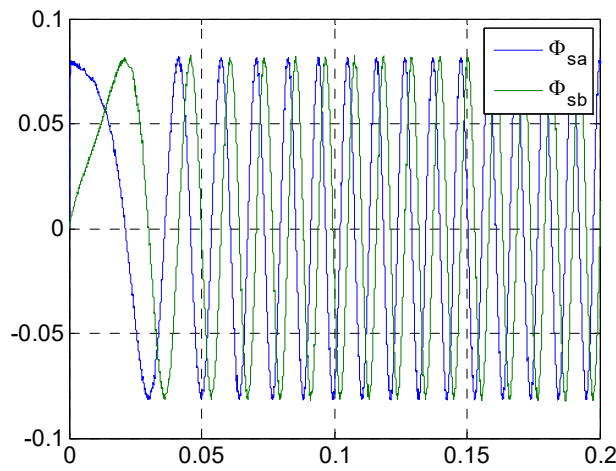

(e) Zoom of the estimated Stator fluxes $(\mathrm{Wb})$ Time (s)

Figure 7. Simulation results for high speed 


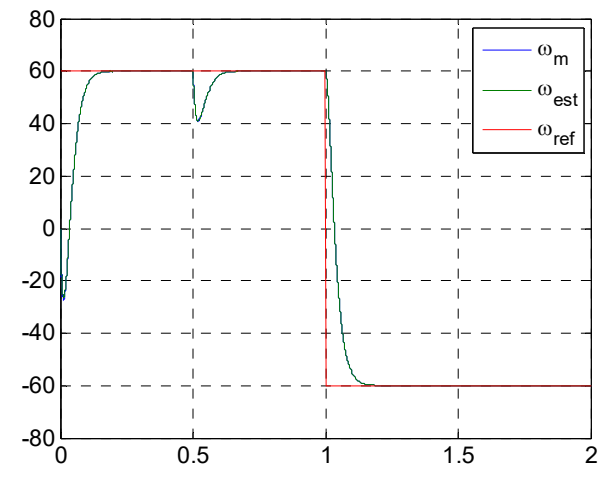

Time (s)

(a) Actual,Estimatd and reference speeds ( $\mathrm{rad} / \mathrm{sec})$

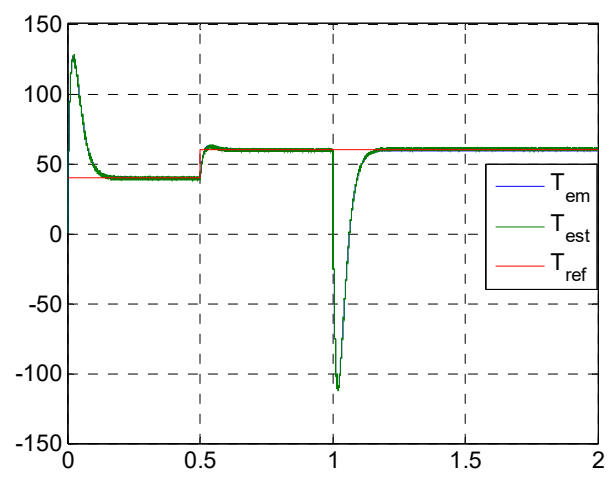

Time (s)

(c) Actual,Estimatd and reference Torques

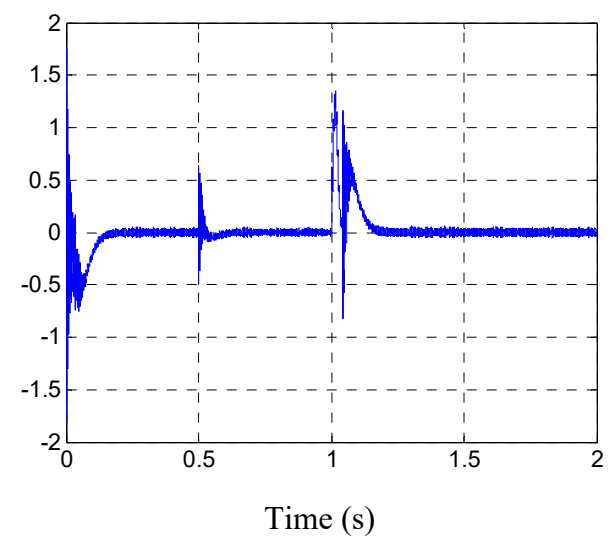

(b) Speed estimation error $(\mathrm{rad} / \mathrm{sec})$

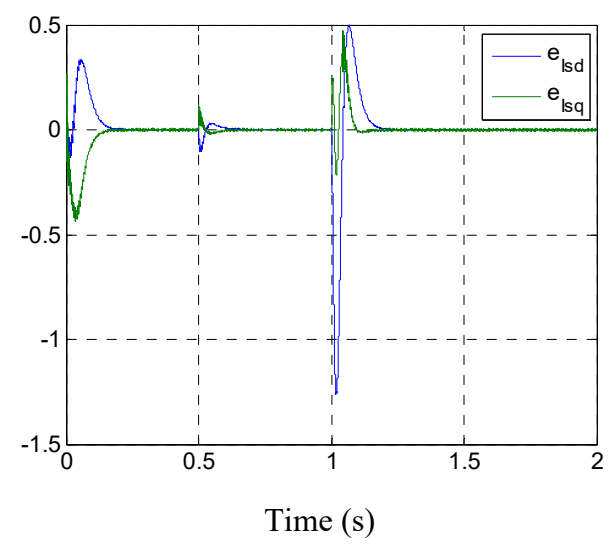

(d) Stator currentserrors (A)

Figure 8. Simulation results for low speed

\section{CONCLUSION}

In this paper, we have used the MRAS technique for speed observation in the sensorless DTC control of the Interior permanent magnet synchronous machine (IPMSM) whose machine model extracts velocity information from measured stator voltages and currents. Using the output of the adjustable model and the reference model the rotor speed and position are estimated. The control of the torque and flux are designed by introducing two multilevel comparators for the flux and the torque to improve the detection of the position of the flux by defining twelve symmetrical sectors in the space of evolution of the flux. Thus, we established a table of commutation with more rules and the voltage vector is more optimal. The simulation results presented have proved the validity of the sensorless DTC control technique with MRAS estimator. Robustness tests are done to highlight the high performance of this proposed strategy.

\section{REFERENCES}

[1] Sekour, M.h., et al., "Sensorless fuzzy direct torque control for high performance electric vehicle with four inwheel motors,"Journal of Electrical Engineering and Technology, vol. 8, no. 3, pp. 530-543, 2013.

[2] Sekour, M., K. Hartani, and A. Merah, "Electric vehicle longitudinal stability control based on a new multimachine nonlinear model predictive direct torque control,"Journal of AdvancedTransportation 2017, 2017.

[3] Hartani, K., Y. Miloud, and A. Miloudi, "Improved direct torque control of permanent magnet synchronous electrical vehicle motor with proportional-integral resistance estimator,"Journal of Electrical Engineering and Technology, vol. 5, no. 3, pp. 451-461, 2010. 
[4] Hartani, K. and A. Draou, "A new multimachine robust based anti-skid control system for high performance electric vehicle,"Journal of Electrical Engineering and Technology, vol. 9, No. 1, pp. 214-230, 2014.

[5] Hartani, K., A. Merah, and A. Draou, "Stability enhancement of four-in-wheel motor-driven electric vehicles using an electric differential system,"Journal of Power Electronics, vol. 15, 5, pp. 1244-1255, 2015.

[6] Yue, Z., C. Wenping, and J. Morrow, "Design of an interior permanent magnet synchronous motor (PMSM) for EV traction,"Transactions of China Electrotechnical Society, vol. 30, no. 14, pp. 108-115, 2015.

[7] Yang, N., et al.,"Interior permanent magnet synchronous motor control for electric vehicle using look-up table," in Proceedings of The 7th International Power Electronics and Motion Control Conference. IEEE, 2012.

[8] Kim, K.-C., "A novel calculation method on the current information of vector inverter for interior permanent magnet synchronous motor for electric vehicle,"IEEE Transactions on Magnetics, vol. 50, No. 2, pp. 829-832, 2014.

[9] Lin, W., et al., "Comparative study on direct torque control of interior permanent magnet synchronous motor for electric vehicle,"IFAC-PapersOnLine, vol. 48, No. 11, pp. 65-71, 2015.

[10] Takahashi, I. and T. Noguchi, "A new quick-response and high-efficiency control strategy of an induction motor,"IEEE Transactions on Industry applications, 1986, no. 5, pp. 820-827.

[11] Takahashi, I. and T. Noguchi, "Take a look back upon the past decade of direct torque control [of induction motors]," in Proceedings of the IECON'97 23rd International Conference on Industrial Electronics, Control, and Instrumentation (Cat. No. 97CH36066), IEEE, 1997.

[12] Yuhendri, M., A. Ahyanuardi, and A. Aswardi, "Direct torque control strategy of PMSM employing ultra sparse matrix converter,"International Journal of Power Electronics and Drive Systems, vol. 9, no. 1, pp. 64, 2018.

[13] Chikh, K., et al., "A constant switching frequency DTC for PMSM using low switching losses SVM-an experimental result," International Journal of Power Electronics and Drive Systems (IJPEDS), vol. 8, No. 2, pp. 558, 2017.

[14] Rodriguez, J., J.-S. Lai, and F.Z. Peng, "Multilevel inverters: a survey of topologies, controls, and applications," IEEE Transactions on industrial electronics, vol. 49, no. 4, pp. 724-738, 2002.

[15] Serpa, L.A., "Current control strategies for multilevel grid connected inverters,"ETH Zurich, 2007.

[16] Anantha, S., et al.,"Speed control of IPMSM motor without rotor position sensors based on MRAS observer with space vector modulation," in 2016 IEEE International Conference on Recent Trends in Electronics, Information \& Communication Technology (RTEICT), IEEE, 2016.

[17] Shi, Y., et al.,"A fuzzy logic based parameter auto-tuning method in MRAS for sensorless interior permanent magnet synchronous motor drives with cyclic fluctuating load," in 2013 International Conference on Electrical Machines and Systems (ICEMS), IEEE, 2013.

[18] Xi, X., et al.,"A sensorless control based on MRAS method in interior permanent-magnet machine drive," in 2005 International Conference on Power Electronics and Drives Systems, IEEE, 2005.

[19] Lazi, J.M., et al., "Speed and position estimator of for sensorless PMSM drives using adaptive controller,"International Journal of Power Electronics and Drive Systems (IJPEDS), vol. 10, 1, pp. 128, 2019.

[20] Azazi, H.Z., M. Metwally, and Z. El-Barbary, "A Cost effective sensorless vector control of 4-switch 3-phase inverter Fed IM using MRAS,"International Journal of Power Electronics and Drive Systems (IJPEDS), vol. 1, No. 2, pp. 113, 2011.

[21] Bellini, A. and S. Bifaretti, "Sensitivity to parameters' variations in sensorless induction motor drives using a reduced order MRAS observer,"International Review Of Electrical Engineering, vol. 2, No. 2, pp. 242-249, 2007.

[22] Brandštetter, P. and M. Dobrovský, "Speed estimation of induction motor using model reference adaptive system with Kalman filter," 2013.

[23] Zhao, Y., W. Qiao, and L. Wu, "Improved rotor position and speed estimators for sensorless control of interior permanent-magnet synchronous machines,"IEEE Journal of Emerging and Selected Topics in Power Electronics, vol. 2, No. 3, pp. 627-639, 2014.

[24] Xu, Y. and Y. Zhong.,"Speed sensorless direct toque control of interior permanent magnet synchronous motor drive based on space vector modulation," in 2010 International Conference on Electrical and Control Engineering, IEEE, 2010.

[25] Hartani, K., et al., "Electronic differential with direct torque fuzzy control for vehicle propulsion system,"Turkish Journal of Electrical Engineering \& Computer Sciences, vol. 17, No. 1, pp. 21-38, 2009. 


\section{BIOGRAPHIES OF AUTHORS}

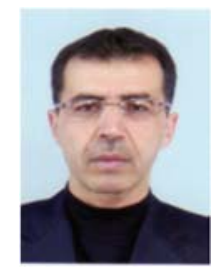

Tahar Terras was born in Saida, Algeria, in 1966. He received the B.S. degree in Electrical Engineering from Djillali Liabes University, Sidi Bel Abbès, Algeria, in 1991 and the M.S. degree from High National Schools of Technical Studies in 2002. Oran, Algeria. He received the Ph.D degree from Djillali Liabes University, Sidi Bel Abbès, Algeria, in 2013. He is currently a member of the Elechtrotechnical Engineering Laboratory, D ${ }^{\mathrm{r}}$; Moulay Tahar University, Saida, Algeria. His research interests include electrical machines and drives, observers and sensorless methods.

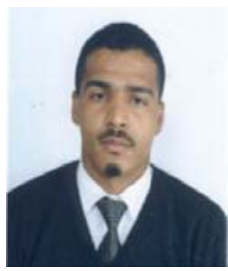

Kada Hartani was born in Saida, Algeria in 1976. He obtained his Doctorate in Electrical Control from the University of Sciences and Technology (USTO), Oran, Algeria, in 2007; M.S. in electrical control from the University of Sciences and Technology (USTO), Oran, Algeria, 2003; B.S. in Electrotechnical Engineering from the University of Saida, Algeria, in 1997. Currently, he is a Professor in electrical control and director of Electrotechnical Engineering Laboratory at the University of Saida, Algeria. His fields of interest include: multi-machines multi-converters systems, antilock brake system, traction control system and anti-skid control for electric vehicle. His fields of interest include multi-machine multi-converter systems, antilock brake system, traction control system, and anti-skid control for electric vehicle. 